\title{
Fuzzy Analogical gates Technique for Heat Integration between Areas
}

\author{
M.H.Hussein \\ Teaching Assistant \\ Chemical Engineering \\ Department - High \\ Institute of Engineering \\ Shorouk City
}

\author{
H.Moselhy \\ Associate Professor \\ Chemical Engineering \\ Department - High \\ Institute of Engineering \\ Shorouk City
}

\author{
S.Aly \\ Professor \\ Chemical and \\ Petroleum Refining \\ Engineering \\ Department - Suez \\ University
}

\author{
M. E. Awad \\ Assistant Professor \\ Chemical and \\ Petroleum Refining \\ Engineering \\ Department - Suez \\ University
}

\begin{abstract}
This paper presents a new technique to synthesis optimum heat integration networks between areas; the algorithm followed for heat recovery problems begins by establishing the minimum energy requirement. For a given network energy consumption, deficit cascades and zone problem table is used to evaluate the minimum number of heat exchanger units. Various network structures may be generated simultaneously to achieve the energy and range targeting. The energy saving and area added are then calculated for different alternative distribution cascades with respect to MER also the number of interzonal transfer. The resulting networks are then subject to fuzzy analogical gates which consists of two analogical gates (symmetric and asymmetric). The symmetric gate (AND gate) inputs are normalized savings in energy requirement and the number of inter-zonal transfer. The asymmetric gate (Invoke gate) inputs are the output of the AND gate and normalized added area. The proposed technique has been applied for the popular and well-known aromatic problem. The results of this case study show that the present strategy is excellent in decision making for the optimum area target and very good indicator to the optimum sequence for alternative distribution cascades compared to total network costs, also robust, accurate and time saver when there are a large number of alternatives possibilities.
\end{abstract}

\section{Keywords}

Energy Savings, Process synthesis, Heat Recovery, Heat Integration Networks, Area Integrity, Fuzzy analogical gates.

\section{INTRODUCTION}

Chemical process design requires the selection of a series of processing steps and their integration to form a complete manufacturing system. The text emphasizes both the design and selection of the steps as individual operations and their integration to form an efficient process. Also, the process will normally operate as part of an integrated manufacturing site consisting of a number of processes serviced by a common utility system. The design of utility systems has been dealt with so that the interactions between processes and the utility system and the interactions between different processes through the utility system can be exploited to maximize the performance of the site as a whole

Chemical processing should form part of a sustainable industrial activity. For chemical processing, this means that processes should use raw materials as efficiently as is economic and practicable, both to prevent the production of waste that can be environmentally harmful and to preserve the reserves of raw materials as much as possible. [1].

Various approaches dealing with the optimum HEN synthesis have been published. Some of them became very popular, such as [2]. The comprehensive overview of HEN synthesis presented by Gundersen and Naess [3] and the overview of process synthesis presented earlier by Nishida et al. [4] provided considerable impetus for further research and development within this field as can be witnessed in the more recent overview by Furman and Sahinidis [5].

However, completing the design of the heat exchanger network is not necessary in order to assess the completed design. Targets can be set for the heat exchanger network to assess the performance of the complete process design without actually having to carry out the network design. These targets allow both energy and capital cost for the heat exchanger network to be assessed. Moreover, the targets allow the designer to suggest process changes for the reactor and separation and recycle systems to improve the targets for energy and capital cost of the heat exchanger network.

Using targets for the heat exchanger network, rather than designs, allows many design options for the overall process to be screened quickly and conveniently. Screening many design options by completed designs is usually simply not practical in terms of the time and effort required. First consider the details of how to set energy targets. Capital cost targets will be considered also, energy targets will be used to suggest design improvements.

Setting targets for heat integration was widely publicized by Linnhoff et al. [6], followed by Smith in a series of his book, an early work Smith [7], the Russian version [8]. The second edition of Linnhoff et al. [9] was elaborated on by Kemp [10]. A very good analysis has been developed by Gundersen [11] in his chapter of the process integration Handbook edited by Klemes [12]. Gundersen [11] summarized the important elements in basic Pinch Analysis as:

(a) Performance Targets ahead of design,

(b) The Composite Curves

(c) The fundamental Pinch Decomposition into a heat deficit region and a heat surplus region

Heat recovery between hot and cold streams is restricted by the shapes of the composite curves and the fact that heat can only be transferred from higher to lower temperatures. The minimum allowed temperature difference $(\Delta \mathrm{T} \min )$ is an economic parameter that indicates a near-optimal trade-off between investment cost (Heat Exchangers- HE) and operating cost (energy). The point of smallest vertical distance (equal to $\Delta T$ min) between the composite curves represents a bottleneck for heat recovery and is referred to as the Heat Recovery Pinch. Hot streams (heat sources) contribute to a set of temperature intervals ('warehouses' of heat), whilst cold streams (heat sinks) draw heat from the same intervals. The temperature intervals are established on the basis of the supply and target temperatures of all process streams. A heat balance is made for each temperature interval, and any heat surplus from that interval is cascaded (thus the name) down to 
the next interval with lower temperatures. The Heat Cascade also referred to as the Heat Surplus Diagram, a very important tool for studying the interface between the process and the utility system (consumption and generation of various types of utilities, both load and level) and for evaluating the HI of special equipment into the process schemes. The important property of the Heat Recovery Pinch is that it decomposes the process into a heat deficit region Above Pinch and a heat surplus region Below Pinch Klemes [13].

In this paper a new technique to synthesis optimum heat integration networks between areas has been presented; the proposed method consists of four sequential steps. Two analogical gates (symmetric and asymmetric) are employed. The symmetric gate (AND gate) inputs are normalized savings in energy requirement and the number of inter-zonal transfer. The asymmetric gate (Invoke gate) inputs are the output of the AND gate and normalized added area. The proposed method has been applied for the popular and wellknown aromatic problem. The results of this case study show that the present strategy is excellent in decision making for the optimum area target and very good indicator to the optimum sequence for alternative distribution cascades compared to total network costs, also robust, accurate and time saver when there are a large number of alternatives possibilities.

\section{PROBLEM STATEMENT}

Process plants are often divided into logically identifiable regions, each having associated processing tasks. Such regions are necessary when considering the practical features of plant design such as operational flexibility, safety, plantlayout, etc. The regions are therefore more generally described as "areas of integrity". It is straightforward now days to predict the minimum overall energy consumption for such heat integrated systems. However, this can be achieved by several different schemes for heat flows between the areas. The task then becomes identifying those schemes which offer maximum area integrity when seeking minimum energy, with the least number of interconnections between the regions / interzonal transfer [14].

This paper develops some understanding of the problem and gives a procedure for finding the saving in energy and area. Thereafter, a new technique is shown which lead to the optimum area target by using fuzzy analogical gates.

\section{AREA INTEGRITY}

For heat recovery, the designer should seek to identify scheme which maximize integrity whilst minimizing energy consumption and to make these areas as self contained as possible.

By decomposing the overall problem in such a manner, the engineer ends up designing networks that are 'local' in terms of operation and can therefore be easily understood by the plant operators. These networks are also associated with 'local' unit operations, etc. and are therefore unlikely to result in unnecessarily expensive pipe runs. Finally, rather than dealing with a single large networking problem, the designer is handling a small number of sub-problems dealing with far fewer streams. The design of these individual networks is likely to be far simpler than developing a network for the overall problem. The designer will often be able to solve the series of sub-problems faster, and to better effect, than the overall problem. Ahmad [14] method's of determining the scope for transferring heat between the zones is quite complicated.

\section{ZONAL PROBLEM TABLE}

The heat flow analysis underlying most approaches to heat recovery network synthesis is the Problem Table Algorithm introduced by Linnhoff and Flower [15]. This algorithm employed three principles. First, it recognized that temperature approach constraints could be handled by adjusting the temperature scales of the hot and cold streams. Second, heat balance should be conducted at identified temperature levels. Third, any subsequent heat surplus from one level could be used to satisfy a deficit at a lower temperature level Amidpour [16]. Given these principles the Problem Table Algorithm consists of the following distinct stages:

i. The stream inlet and outlet temperatures are adjusted for minimum temperature approach. The adjusted temperatures are called 'interval temperatures'.

ii. The 'interval temperatures' are ranked. Each individual value then provides the boundary of an interval in which a heat balance is subsequently to be made. Intervals run from the hot to the cold end of the process.

iii. Heat balances are conducted in each temperature interval and the 'surplus' heat available from that interval determined

iv. The 'surpluses' are now 'cascaded' down the temperature intervals starting at the hot end of the Table.

v. The largest 'negative surplus' (i.e. deficit) in the resultant cascade gives the heating requirement of the process. When this heat is added to the top of the 'table' and cascaded down the entire negative values disappear. A zero value appears at the location of the largest deficit (which is also the Pinch location).

The concept of 'zoning' (or, area integrity) can easily be introduced into this algorithm by using an adaptation similar to that introduced by Kemp and Deakin [17] to analyze batch processes. The temperature intervals for the overall process are determined (just as if the treatment was for a single problem) but the streams are separated into individual zones and cascades developed across these intervals for each zone. A typical cascades result might be presented in Table 1 .

Examination of this table shows that Zone A has a Pinch at the boundary of intervals 3 and 4 and would require 13 units of heat if it is to operate independently. Zone B has a Pinch at the boundary of intervals 4 and 5 and requires 15 units of heat for independent operation. Zone $\mathrm{C}$ has a Pinch at the boundary of intervals 1 and 2 and requires 4 units of heat for independent operation.

Summing these individual needs indicates that if all of the zones were to operate independently 32 units of heat would be needed. Since, the zonal heat balances are all conducted in the same temperature intervals the cascades can be summed across the zones in order to obtain the cascade for the overall process. Examination of the overall cascade indicates that the Pinch for the overall process occurs at the boundary between intervals 3 and 4 and that the overall process requires just 22 units of heat. Thus, the scope for energy saving through interzonal transfer is seen to be 10 units.

The options for inter-zonal transfer can be identified in the following way. First, a distribution of the minimum utility is selected (this can be varied later). One option for the problem under consideration would be to add 4 units to Zone $\mathrm{C}$ (which has the highest Pinch location), 13 units to Zone A (which has 
the next highest Pinch location) and the remaining 5 units to Zone B.

The effects of this distribution on the individual cascades is then determined (see Table 2). With the chosen utility distribution all of the negative elements have been removed from Zones $\mathrm{A}$ and $\mathrm{C}$ and the largest deficit in Zone $\mathrm{B}$ is 10 units (as expected). The remaining negative elements $(-7$ in interval 3, and - 10 in interval 4 of zone B) can be removed by transferring heat from one zone to another.

The table shows the options. The deficit of 7 units in Zone B can be removed by transferring 7 units of heat from Zone $\mathrm{C}$ to Zone B at interval 3 (or higher) as shown in Table 3.

It is impossible to transfer more than this without generating a deficit in Zone C. As a result of this transfer the deficit in interval 4 of zone B is reduced from 10 to 3 units whilst the surplus in interval 4 of Zone $\mathrm{C}$ is decreased from 14 to 7 units. Obviously, the Zone B deficit can be removed through a further transfer from Zone $\mathrm{C}$, this time from interval 4.

The 'Zonal Problem Table' clearly show the energy costs associated with operating the individual plant areas independently and the options for making energy savings by inter-zonal transfers [16].

\section{STREAM CASCADES TABLES}

The 'Zonal Problem Table' indicates what energy transfers can take place between the individual plant zones. It does not give any indication of how energy transfer can or should be accomplished. For this, individual streams must be considered.

Rather than develop the Problem Table from individual heat balances, it could be developed from individual stream cascades (in the same way the overall cascade is developed from the zonal cascades). A table for this problem could be that shown in Table 4. It can be used to identify exactly what streams should be involved in the zonal transfer.

Note: once a stream enters the cascade its heat must be cascaded down through all lower temperature intervals. A stream (such as stream H3 in Table 4) may only by physically present in the first interval. However, its contribution to the cascade must appear in all intervals. For instance, the initial analysis conducted above indicated a need to transfer 7 units of heat from Zone $\mathrm{C}$ to Zone $\mathrm{B}$ at interval 3 or higher. Examination of Table 4 shows the available options. Stream $\mathrm{H} 3$ could be used. However, this will only provide 5 units of heat. Stream $\mathrm{H} 2$ can be used and is able to provide the full transfer. Stream H1 does not enter the cascade until Interval 4 so cannot be used.

There was also a need to transfer 3 units of heat from interval 4. The stream cascades show that stream $\mathrm{H} 2$ cannot be used for this purpose because it is only present in intervals 2 and 3 . A transfer involving stream $\mathrm{H} 1$ is the only available option. So by studying the stream cascades for the two zones it is possible to identify which streams could and should be involved in zonal transfers.

\section{TARGETS: A NEW APPROACH TO AREA INTEGRITY BY FUZZY ANALOGICAL GATES STRATEGY}

The algorithm followed here is obtaining the optimum target area, most of procedures for heat recovery problems begin by establishing the minimum energy requirement, for a given network energy consumption, deficit cascades and zone problem table is used to evaluate the minimum number of heat exchanger units. Subsequently, various network structures may be generated to simultaneously achieve the energy and range targeting. The saving of energy and area are then calculated for different alternative distribution cascades with respect to MER also the number of interzonal transfer. The resulting networks are then subject to fuzzy analogical gates to get the optimum area target as shown in Fig. 1.

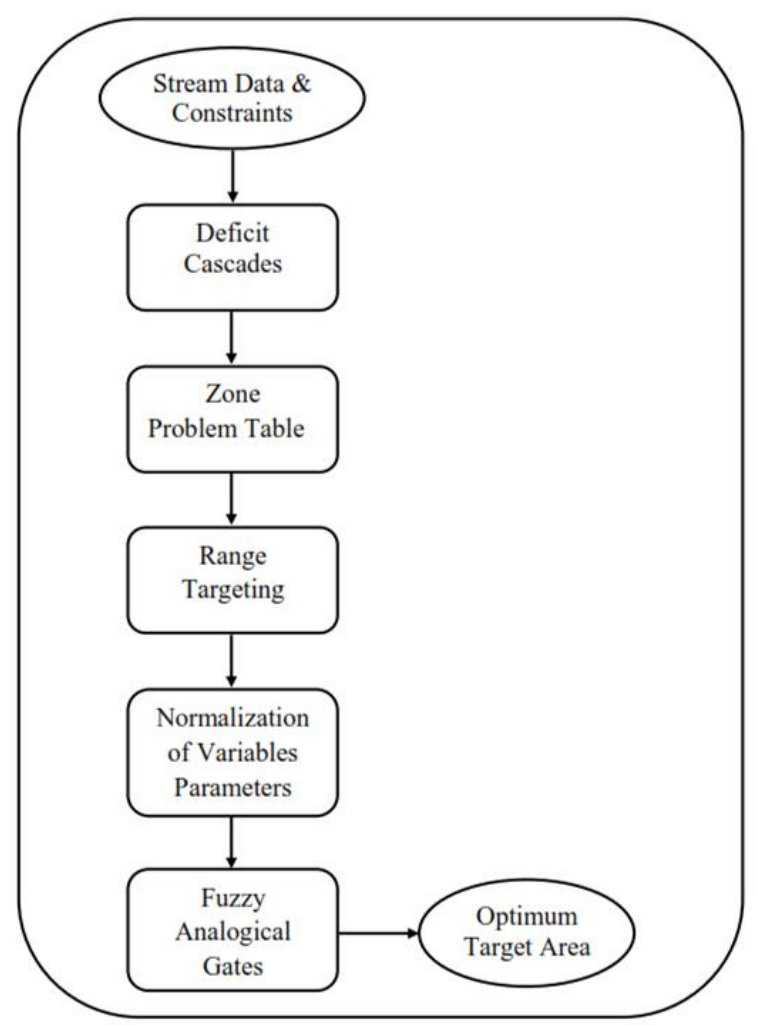

Fig.1. Overall Procedure for designing optimum target area using fuzzy analogical gates techniques

\subsection{Step 1. Normalization of variables parameters}

This step is a simple preparation for the inputs data to the analogical gates. First, we determine the saving in energy requirements, and then normalize its value according to equation (1). Second normalize the number of interzonal transfer and area added according to equation (2).

$$
\begin{aligned}
& \mu_{1}=\left(\frac{f-f_{\min }}{f_{\max }-f_{\min }}\right) \quad\left\{\begin{array}{l}
\mu=0, f=f_{\text {min }} \\
\mu=1, f=f_{\max }
\end{array}\right. \\
& \mu_{2}, \mu_{3}=\left(\frac{f-f_{\max }}{f_{\text {min }}-f_{\text {max }}}\right) \quad\left\{\begin{array}{l}
\mu=0, f=f_{\text {max }} \\
\mu=1, f=f_{\text {min }}
\end{array}\right.
\end{aligned}
$$

6.2. Step 2.Fuzzy Analogical Gates Network Two fuzzy analogical gates will be used sequentially as shown in Fig.2. The first gate is selected to be symmetric and the second gate is asymmetric. A fuzzy analogical - AND gate will be followed by a fuzzy invoke gate Hussein [18] .

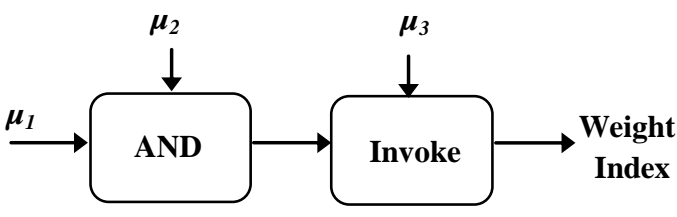

Fig.2. Fuzzy analogical gates network. 
The symmetric gate inputs are normalized savings in energy requirement $\boldsymbol{\mu}_{1}$ and the number of inter-zonal transfer $\boldsymbol{\mu}_{2}$. The asymmetric gate inputs are the output of the symmetric gate and normalized added area $\boldsymbol{\mu}_{3}$.

\subsection{Step 3.Choice of the Best Weight Index}

The final step corresponds to the choice of the best weight Index. The operation is carried out by comparing (W.I) values for all solution of network configuration and by choosing the greatest one which is the optimum area target.

W.I optimum $=\max \left\{\mathrm{W} . \mathrm{I}_{1}, \mathrm{~W} . \mathrm{I}_{2}, \mathrm{~W} . \mathrm{I}_{3} \ldots \ldots\right\}$

\section{AROMATICS CASE STUDY}

The use of these expanded 'Problem Tables' can be demonstrated using the problem derived by Ahmad [14]. The stream data for the problem is given in Table 5. The flowsheet for the process is given in Figure 3.

The problem has been divided into the three zones. The first zone incorporates reactor 1 , separator 1 and distillation column 1 . The second zone contains reactor 2 and separator 2 . The third zone only contains distillation column 2 . This may not be the best zoning arrangement. Research into the selection of zone boundaries is under way. The deficit cascades are presented in Table 6 .

Table 7 shows that the utilities needed to run each zone independently sums to $69.5 \mathrm{MW}$ (43, 1.5 and 25) The network area requirement was found to be $20,806 \mathrm{~m}^{2}$ and the total annual cost was $\$ 8.61 \mathrm{M}$ whereas the minimum utility requirement for the overall problem is $30.55 \mathrm{MW}$ (a difference of $38.95 \mathrm{MW}$ ). It is further seen that the Pinch in Zone $\mathrm{B}$ is at an interval temperature of 495 degrees, that in Zone $\mathrm{C}$ at 205 degrees, and that in Zone $\mathrm{A}$ at 65 degrees. Two potential initial utility distributions are suggested. First, all utility could be provided at the highest level, totally catering for the demands of Zones B and C (the zones having the highest Pinch temperatures), whilst placing the residual in Zone A. Alternatively, utilities at more than one temperature level could be used. The overall cascade indicates a need for 5.5 units of high temperature utility (see overall cascade to interval 6) with 25.05 going into Zone A at a much lower level (see Table 8).

In this case 3 units of heat will be added at the top of the zone A cascade (to eliminate the deficit in zone 3 ). The remaining 2.5 units of highest temperature utility will be added to zone B Each distribution will be examined in turn. For the first distribution the first deficit occurs in Zone A at interval 10 (see Table 9). To overcome this deficit transfers of 24 units of heat from Zone B and 4.95 units from Zone C are needed. The results of these transfers on the zonal cascades are shown in Table 10.The transfer from Zone $\mathrm{C}$ leads to a deficit of 1.45 units at interval 11 .

This can be eliminated by a transfer from Zone B (developed through Table 10). The next deficit occurs in interval 14 and by transferring 10 units from Zone $\mathrm{C}$ to Zone $\mathrm{A}$ and 6.1 units from Zone $\mathrm{C}$ to Zone $\mathrm{B}$ this, and all subsequent ones, are removed. A system exhibiting the minimum utility requirement has now been established. It is a complex one involving 5 inter- zonal transfers (see Figure 4).
Table 1. Zonal heat cascades.

\begin{tabular}{ccccc}
\hline Interval & Zone A & Zone B & Zone C & Overall \\
\hline 1 & 5 & 3 & -4 & 4 \\
2 & -5 & 5 & 7 & 7 \\
3 & -13 & 12 & 3 & -22 \\
4 & 7 & -15 & 10 & 2 \\
5 & 17 & 3 & 7 & 27 \\
\hline
\end{tabular}

Table 2. Cascade after utility distribution.

\begin{tabular}{ccccc}
\hline Interval & Zone A & Zone B & Zone C & Overall \\
\hline Addition & 13 & 5 & 4 & 22 \\
1 & 18 & 8 & 0 & 26 \\
2 & 8 & 10 & 11 & 29 \\
3 & 0 & -7 & 7 & 0 \\
4 & 20 & -10 & 14 & 24 \\
5 & 30 & 8 & 11 & 49 \\
\hline
\end{tabular}

Table 3. Cascade after first inter-zonal transfer.

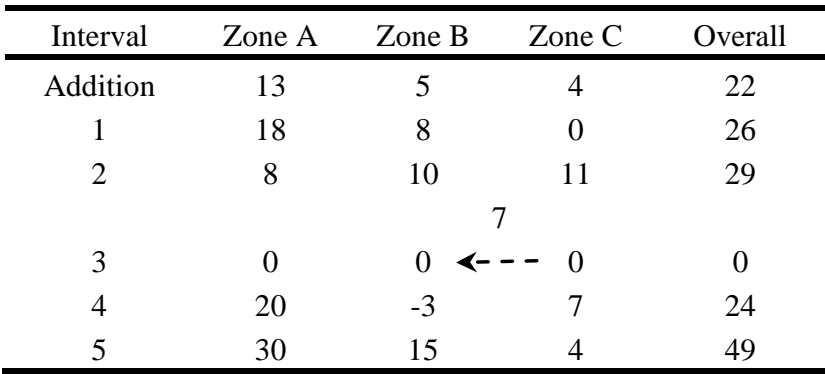

Table 4. Stream cascades for zone $C$

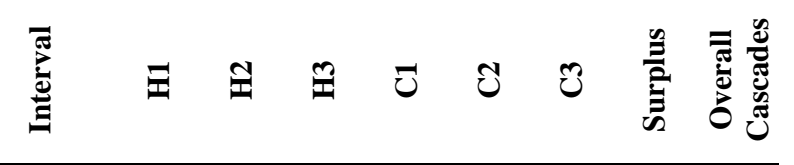

\begin{tabular}{|c|c|c|c|c|c|c|c|c|}
\hline Addition & & & & & & & & 4 \\
\hline 1 & & & 5 & -9 & & & -4 & 0 \\
\hline 2 & & 11 & 5 & -9 & & & 7 & 11 \\
\hline 3 & & 22 & 5 & -9 & -15 & & 3 & 7 \\
\hline 4 & 22 & 22 & 5 & -9 & -30 & & 10 & 14 \\
\hline 5 & 35 & 22 & 5 & -9 & -30 & -20 & 7 & 11 \\
\hline
\end{tabular}

Table 5. Ahmad and Hui problem: stream data.

\begin{tabular}{ccccccc}
\hline Stream & Zone & Type & $\begin{array}{c}\mathbf{T}_{\mathbf{S}} \\
\left({ }^{\circ} \mathbf{C}\right)\end{array}$ & $\begin{array}{c}\mathbf{T}_{\mathbf{T}} \\
\left({ }^{\circ} \mathbf{C}\right)\end{array}$ & $\begin{array}{c}\mathbf{C P} \\
\left(\mathbf{M W} /{ }^{\circ} \mathbf{C}\right)\end{array}$ & $\begin{array}{c}\mathbf{Q} \\
(\mathbf{M W})\end{array}$ \\
\hline 1 & A & Hot & 300 & 60 & 0.30 & 72.00 \\
2 & A & Hot & 70 & 69 & 25.0 & 52.00 \\
3 & A & Cold & 30 & 300 & 0.30 & -81.00 \\
4 & A & Cold & 35 & 100 & 0.25 & -16.25 \\
5 & A & Cold & 139 & 140 & 30.0 & -30.00 \\
6 & B & Hot & 500 & 120 & 0.25 & 95.00 \\
7 & B & Cold & 139 & 500 & 0.15 & -54.15 \\
\hline 8 & B & Cold & 20 & 250 & 0.10 & -23.00 \\
9 & C & Hot & 120 & 119 & 15.0 & 15.00 \\
10 & C & Hot & 200 & 30 & 0.20 & 34.00 \\
11 & C & Cold & 110 & 160 & 0.25 & -12.50 \\
12 & C & Cold & 200 & 201 & 25.0 & -25.00 \\
\hline
\end{tabular}


Table 6. Zone deficit cascades.

\begin{tabular}{cccccc}
\hline Interval & $\mathbf{T}_{\mathbf{S}}-\mathbf{T}_{\mathbf{T}}$ & $\begin{array}{c}\text { Zone } \\
\mathbf{A}\end{array}$ & $\begin{array}{c}\text { Zone } \\
\mathbf{B}\end{array}$ & $\begin{array}{c}\text { Zone } \\
\mathbf{C}\end{array}$ & Overall \\
\hline $\mathbf{1}$ & $505-495$ & & -1.5 & & -1.5 \\
$\mathbf{2}$ & $495-305$ & & 17.5 & & 17.5 \\
$\mathbf{3}$ & $305-295$ & -3 & 18.5 & & 15.5 \\
$\mathbf{4}$ & $295-255$ & -3 & 22.5 & & 19.5 \\
$\mathbf{5}$ & $255-206$ & -3 & 22.5 & & 19.5 \\
$\mathbf{6}$ & $206-205$ & -3 & 22.5 & -25 & -5.5 \\
$\mathbf{7}$ & $205-195$ & -3 & 22.5 & -25 & -5.5 \\
$\mathbf{8}$ & $195-165$ & -3 & 22.5 & -19 & 0.5 \\
$\mathbf{9}$ & $165-145$ & -3 & 22.5 & -20 & 0.5 \\
$\mathbf{1 0}$ & $145-144$ & -33 & 22.5 & -20.05 & -30.55 \\
$\mathbf{1 1}$ & $144-115$ & -33 & 26.85 & -21.5 & -27.65 \\
$\mathbf{1 2}$ & $115-114$ & -33 & 26.75 & -6.3 & -12.55 \\
$\mathbf{1 3}$ & $114-105$ & -33 & 25.85 & -4.5 & -11.65 \\
$\mathbf{1 4}$ & $105-65$ & -43 & 21.85 & 3.5 & -17.65 \\
$\mathbf{1 5}$ & $65-64$ & -18.25 & 21.75 & 3.7 & 7.2 \\
$\mathbf{1 6}$ & $64-55$ & -20.5 & 20.85 & 5.5 & 5.85 \\
$\mathbf{1 7}$ & $55-40$ & -28.75 & 19.35 & 8.5 & -0.9 \\
$\mathbf{1 8}$ & $40-35$ & -30.25 & 18.85 & 9.5 & -1.9 \\
$\mathbf{1 9}$ & $35-25$ & -30.25 & 17.85 & 11.5 & -0.9 \\
\hline
\end{tabular}

Table 7. Distributed cascades

\begin{tabular}{ccccc}
\hline Interval & Zone A & Zone B & Zone C & Overall \\
\hline Utility & 4.05 & 1.5 & 25 & 30.55 \\
1 & & 0 & & 29.05 \\
2 & & 19 & & 48.05 \\
3 & 1.05 & 20 & & 46.05 \\
4 & 1.05 & 24 & & 50.05 \\
5 & 1.05 & 24 & & 50.05 \\
6 & 1.05 & 24 & 0 & 25.05 \\
7 & 1.05 & 24 & 0 & 25.05 \\
8 & 1.05 & 24 & 6 & 31.05 \\
9 & 1.05 & 24 & 5 & 31.05 \\
10 & -28.95 & 24 & 4.95 & 0 \\
11 & -28.95 & 28.35 & 3.5 & 2.9 \\
12 & -28.95 & 28.25 & 18.7 & 18 \\
13 & -28.95 & 27.35 & 20.5 & 18.9 \\
14 & -38.95 & 23.35 & 28.5 & 12.9 \\
15 & -14.2 & 22.35 & 28.7 & 37.75 \\
16 & -16.45 & 23.25 & 30.5 & 36.4 \\
17 & -24.7 & 20.85 & 33.5 & 29.65 \\
18 & -26.2 & 20.35 & 34.5 & 28.65 \\
19 & -26.2 & 19.35 & 36.5 & 29.65 \\
\hline
\end{tabular}

Table 8. Distributed cascades

\begin{tabular}{ccccc}
\hline Interval & Zone A & Zone B & Zone C & Overall \\
\hline Utility & 3 & 2.5 & 0 & 5.5 \\
level 1: & & 1 & & 4 \\
$\mathbf{1}$ & & 20 & & 23 \\
$\mathbf{2}$ & & 21 & & 21 \\
$\mathbf{3}$ & 0 & 25 & & 25 \\
$\mathbf{4}$ & 0 & 25 & & 25 \\
$\mathbf{5}$ & 0 & 25 & -25 & 0 \\
$\mathbf{6}$ & 0 & 25 & -25 & 0 \\
$\mathbf{7}$ & 0 & 25 & -25 & 6 \\
$\mathbf{8}$ & 0 & 25 & -25 & 5 \\
$\mathbf{9}$ & 0 & & & \\
Utility & 25.05 & & & \\
level 2: & -4.95 & 25 & -20.05 & 0 \\
$\mathbf{1 0}$ & -4.95 & 29.35 & -21.5 & 2.9 \\
$\mathbf{1 1}$ & -4.95 & 29.25 & -6.3 & 18 \\
$\mathbf{1 2}$ & -4.95 & 28.35 & -4.5 & 18.9 \\
$\mathbf{1 3}$ & -14.95 & 24.35 & 3.5 & 12.9 \\
$\mathbf{1 4}$ & & & &
\end{tabular}

\begin{tabular}{ccccc}
\hline Interval & Zone A & Zone B & Zone C & Overall \\
\hline $\mathbf{1 5}$ & 9.8 & 24.25 & 3.7 & 37.75 \\
$\mathbf{1 6}$ & 7.55 & 23.35 & 5.5 & 36.4 \\
$\mathbf{1 7}$ & -0.7 & 21.85 & 8.5 & 29.65 \\
$\mathbf{1 8}$ & -2.2 & 21.35 & 9.5 & 28.65 \\
$\mathbf{1 9}$ & -2.2 & 20.35 & 11.5 & 29.65 \\
\hline
\end{tabular}

Table 9. Distributed cascade

\begin{tabular}{ccccc}
\hline Interval & Zone A & Zone B & Zone C & Overall \\
\hline Utility & 4.05 & 1.5 & 25 & 30.55 \\
$\mathbf{1}$ & & 0 & & 29.05 \\
$\mathbf{2}$ & & 19 & & 48.15 \\
$\mathbf{3}$ & 1.05 & 20 & & 46.05 \\
$\mathbf{4}$ & 1.05 & 24 & & 50.05 \\
$\mathbf{5}$ & 1.05 & 24 & & 50.05 \\
$\mathbf{6}$ & 1.05 & 24 & 0 & 25.05 \\
$\mathbf{7}$ & 1.05 & 24 & 0 & 25.05 \\
$\mathbf{8}$ & 1.05 & 24 & 6 & 31.05 \\
$\mathbf{9}$ & 1.05 & 24 & 5 & 31.05 \\
& $\mathbf{4}--$ & $4.95-----$ & \\
$\mathbf{1 0}$ & $\mathbf{4}-24$ & ---- & & \\
$\mathbf{1 1}$ & 0 & 0 & 0 & 0.0 \\
$\mathbf{1 2}$ & 0 & 4.35 & -1.45 & 2.9 \\
$\mathbf{1 3}$ & 0 & 4.25 & 13.75 & 18 \\
$\mathbf{1 4}$ & -10 & 3.35 & 15.55 & 18.9 \\
$\mathbf{1 5}$ & 14.75 & -0.65 & 23.55 & 12.9 \\
$\mathbf{1 6}$ & 12.5 & -0.75 & 23.75 & 37.75 \\
$\mathbf{1 7}$ & 4.25 & -3.65 & 25.55 & 36.4 \\
$\mathbf{1 8}$ & 2.75 & -3.65 & 28.55 & 29.65 \\
$\mathbf{1 9}$ & 2.75 & -4.65 & 31.55 & 28.65 \\
& & & & 29.65 \\
\hline
\end{tabular}

Individual transfers can now be relaxed in order to obtain alternatives systems. For instance, the transfer of $4.95 \mathrm{MW}$ from Zone $\mathrm{C}$ to Zone $\mathrm{A}$ at interval 10 resulted in an immediate deficit of $1.45 \mathrm{MW}$ in Zone C/interval 11. This deficit could be eliminated by reducing the transfer from interval 10 and making up the shortfall through the provision of additional utility. The result is a distribution involving 4 (rather than 5) inter-zonal transfers but requiring $32 \mathrm{MW}$ of utility (Rather than $30.55 \mathrm{MW}$ ).

Table 10. Distributed cascades

\begin{tabular}{|c|c|c|c|c|}
\hline Interval & Zone A & Zone B & Zone C & Overall \\
\hline Utility & 4.05 & 1.5 & 25 & 30.55 \\
\hline 1 & & 0 & & 29.05 \\
\hline 2 & & 19 & & 48.15 \\
\hline 3 & 1.05 & 20 & & 46.05 \\
\hline 4 & 1.05 & 24 & & 50.05 \\
\hline 5 & 1.05 & 24 & & 50.05 \\
\hline 6 & 1.05 & 24 & 0 & 25.05 \\
\hline 7 & 1.05 & 24 & 0 & 25.05 \\
\hline 8 & 1.05 & 24 & 6 & 31.05 \\
\hline 9 & 1.05 & 24 & 5 & 31.05 \\
\hline \multicolumn{5}{|c|}{$4----4 \quad 4.95 \quad \cdots-\cdots$} \\
\hline \multicolumn{5}{|c|}{$---1.45->$} \\
\hline 11 & 0 & 2.9 & 0 & 2.9 \\
\hline 12 & 0 & 2.8 & 15.2 & 18 \\
\hline 13 & 0 & 1.9 & 17 & 18.9 \\
\hline \multicolumn{5}{|c|}{$\begin{array}{r}<---10<--\cdots \\
\quad \leftarrow-6.1--\end{array}$} \\
\hline 14 & 0 & 4 & 8.9 & 12.9 \\
\hline 15 & 24.75 & 3.9 & 9.1 & 37.75 \\
\hline
\end{tabular}




\begin{tabular}{ccccc}
\hline Interval & Zone A & Zone B & Zone C & Overall \\
\hline 16 & 22.5 & 3 & 10.9 & 36.4 \\
17 & 14.25 & 1.5 & 13.9 & 29.65 \\
18 & 12.75 & 1 & 14.9 & 28.65 \\
19 & 12.75 & 0 & 16.9 & 29.65 \\
\hline
\end{tabular}

The alternatives derived through this progressive relaxation are shown in Figure 4 and Table11.

Table 11. Alternative Utility Distribution data for Figure 4

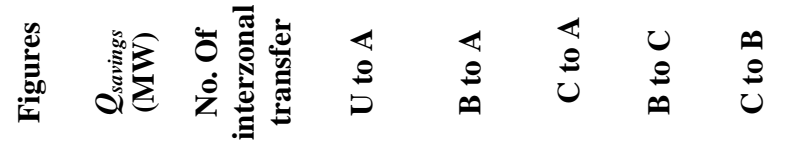

\begin{tabular}{cccccccc}
\hline (a) & 38.95 & 5 & - & 24 & 10 & 1.45 & 6.1 \\
(b) & 24 & 2 & 14.95 & 24 & - & 4.65 & - \\
(c) & 37.5 & 4 & 1.45 & 24 & 10 & - & 4.65 \\
(d) & 29.35 & 2 & 9.6 & 19.35 & 10 & - & - \\
(e) & 34 & 3 & 4.95 & 24 & 10 & 4.65 & - \\
(f) & 19.35 & 1 & 19.6 & 19.35 & - & - & - \\
\hline
\end{tabular}

A similar development has been applied to the second potential utility distribution (see Tables 13 and 14). The results given for Figure 5 in Table12.

Table 12. Alternative Utility Distribution data for Figure 5

\begin{tabular}{|c|c|c|c|c|c|c|c|c|}
\hline 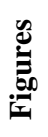 & 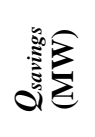 & 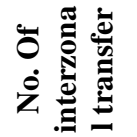 & $\begin{array}{l}\varangle \\
\stackrel{8}{b}\end{array}$ & $\stackrel{\oplus}{\stackrel{\theta}{\nu}}$ & $\begin{array}{l}0 \\
\rho \\
\rho\end{array}$ & $\stackrel{\leftarrow}{\varrho}$ & U & $\stackrel{\rho}{\rho}$ \\
\hline
\end{tabular}

\begin{tabular}{ccccccccc}
\hline (a) & 38.95 & 5 & - & - & - & 4.95 & 25 & 6.1 \\
(b) & 34 & 4 & - & 4.95 & - & 10 & 25 & 4.65 \\
(c) & 37.5 & 4 & - & - & 1.45 & 3.5 & 25 & 4.65 \\
(d) & 24 & 2 & 10 & 4.95 & - & 10 & - & - \\
(e) & 32.85 & 3 & - & - & - & 3.5 & 25 & 4.65 \\
(f) & 19.35 & 1 & - & - & - & 10 & - & - \\
(g) & 29.35 & 2 & - & 6.1 & - & 3.5 & 25 & - \\
(h) & 22.85 & 2 & 10 & 9.6 & - & 19 & 25 & - \\
\hline
\end{tabular}

Table 13. Distributed cascades

\begin{tabular}{ccccc}
\hline Interval & Zone A & Zone B & Zone C & Overall \\
\hline $\begin{array}{c}\text { Utility } \\
\text { level 1: }\end{array}$ & 3 & 2.5 & 0 & 5.5 \\
$\mathbf{1}$ & & 1 & & 4 \\
$\mathbf{2}$ & & 20 & & 23 \\
\hline $\mathbf{3}$ & 0 & 21 & & 21 \\
$\mathbf{4}$ & 0 & 25 & & 25 \\
$\mathbf{5}$ & 0 & 25 & & 25 \\
& & $---\cdot 25--\boldsymbol{7}$ & \\
$\mathbf{6}$ & 0 & 0 & 0 & 0 \\
$\mathbf{7}$ & 0 & 0 & 0 & 0 \\
$\mathbf{8}$ & 0 & 0 & 6 & 6 \\
$\mathbf{9}$ & 0 & 0 & 5 & 5
\end{tabular}

Utility

25.05

level 2:

10

0

$$
\begin{aligned}
& \leftarrow-4.95-- \\
& 0
\end{aligned}
$$

0

\begin{tabular}{ccccc}
\hline Interval & Zone A & Zone B & Zone C & Overall \\
\hline $\mathbf{1 1}$ & 0 & 4.35 & -1.45 & 2.9 \\
$\mathbf{1 2}$ & 0 & 4.25 & 13.75 & 18 \\
$\mathbf{1 3}$ & 0 & 3.35 & 15.55 & 18.9 \\
$\mathbf{1 4}$ & -10 & -0.65 & 23.55 & 12.9 \\
$\mathbf{1 5}$ & 14.75 & -0.75 & 25.55 & 37.75 \\
$\mathbf{1 6}$ & 12.5 & -1.65 & 28.55 & 36.4 \\
$\mathbf{1 7}$ & 4.25 & -3.15 & 29.55 & 29.65 \\
$\mathbf{1 8}$ & 2.75 & -3.65 & 31.55 & 28.65 \\
$\mathbf{1 9}$ & 2.75 & -4.65 & 12.5 & 29.65 \\
\hline
\end{tabular}

Table 14. Distributed cascades

\begin{tabular}{ccccc}
\hline Interval & Zone A & Zone B & Zone C & Overall \\
\hline Utility & 3 & 2.5 & & 5.5 \\
Level 1: & 0 & 1 & & 4 \\
1 & 0 & 20 & & 23 \\
$\mathbf{2}$ & 0 & 21 & & 21 \\
$\mathbf{3}$ & 0 & 25 & & 25 \\
$\mathbf{4}$ & 0 & 25 & & 25 \\
$\mathbf{5}$ & & $---\cdot 25-->$ & \\
& 0 & 0 & 0 & 0 \\
$\mathbf{6}$ & 0 & 0 & 0 & 0 \\
$\mathbf{7}$ & 0 & 0 & 6 & 6 \\
$\mathbf{8}$ & 0 & 0 & 5 & 5 \\
$\mathbf{9}$ & & &
\end{tabular}

Utility $\quad 25.05$

Level 2:

\begin{tabular}{|c|c|c|c|}
\hline \multicolumn{4}{|c|}{$\leftarrow-4.95---$} \\
\hline 0 & 0 & 0 & 0 \\
\hline & \multicolumn{3}{|c|}{$---\cdot 1.45-->$} \\
\hline 0 & 2.9 & 0 & 2.9 \\
\hline 0 & 2.8 & 15.2 & 18 \\
\hline 0 & 1.9 & 17 & 18.9 \\
\hline$\leftarrow$ & \multirow{2}{*}{\multicolumn{3}{|c|}{$\begin{array}{l}10--\cdots \\
4-6.1 \cdots\end{array}$}} \\
\hline & & & \\
\hline 0 & 4 & 8.9 & 12.9 \\
\hline 24.75 & 3.9 & 9.1 & 37.75 \\
\hline 22.5 & 3 & 10.9 & 36.4 \\
\hline 14.25 & 1.5 & 13.9 & 29.65 \\
\hline 12.75 & 1 & 14.9 & 28.65 \\
\hline 12.75 & 0 & 16.9 & 29.65 \\
\hline
\end{tabular}

The energy savings, added area and the number of interzonal transfers are presented in Table 15.Fuzzy analogical gates results with TAC of networks are shown in Table 16.

Table 15. Utility Distribution data

\begin{tabular}{cccc}
\hline Figures & $\begin{array}{c}\text { Saving } \\
\text { Energy } \\
(\mathbf{M W})\end{array}$ & $\begin{array}{c}\text { No. of interzonal } \\
\text { transfer }\end{array}$ & $\begin{array}{c}\text { Added } \\
\text { Area } \\
\left(\mathbf{m}^{\mathbf{2}}\right)\end{array}$ \\
\hline $\begin{array}{c}\text { Without } \\
\text { Area }\end{array}$ & - & & \\
Integrity & & - & - \\
\hline 4-a & 38.95 & 5 & 15,416 \\
4-b & 24.00 & 2 & 10,911 \\
4-c & 37.50 & 4 & 17,376 \\
4-d & 29.35 & 2 & 8,662 \\
4-e & 34.00 & 3 & 15,624 \\
4-f & 19.35 & 1 & 3,969 \\
5-a & 38.95 & 5 & 826.0 \\
5-b & 34.00 & 3 & 12,367 \\
5-c & 37.50 & 4 & 13,709 \\
5-d & 24.00 & 2 & 7,248 \\
5-e & 32.85 & 3 & 7,208 \\
\hline
\end{tabular}




\begin{tabular}{cccc}
\hline Figures & $\begin{array}{c}\text { Saving } \\
\text { Energy } \\
\text { (MW) }\end{array}$ & $\begin{array}{c}\text { No. of interzonal } \\
\text { transfer }\end{array}$ & $\begin{array}{c}\text { Added } \\
\text { Area } \\
\left(\mathbf{m}^{\mathbf{2}}\right)\end{array}$ \\
\hline $5-\mathrm{f}$ & 19.35 & 1 & 826.0 \\
$5-\mathrm{g}$ & 29.35 & 2 & 5,463 \\
$5-\mathrm{h}$ & 22.85 & 2 & 2,519 \\
\hline
\end{tabular}

Table 16. Fuzzy Analogical gates results

\begin{tabular}{cccccc}
\hline Figures & $\boldsymbol{\mu}_{\boldsymbol{I}}$ & $\boldsymbol{\mu}_{\boldsymbol{2}}$ & $\boldsymbol{\mu}_{\mathbf{3}}$ & $\mathbf{W . I}$ & $\begin{array}{c}\text { TAC } \\
(\mathbf{M} \mathbf{\$} / \mathbf{Y} \mathbf{r})\end{array}$ \\
\hline $\begin{array}{c}\text { Without } \\
\text { Area }\end{array}$ & - & - & - & - & 8.61 \\
Integrity & & & & & \\
\hline 4-a & 1.000 & 0.000 & 0.118 & 0.000 & 4.97 \\
4-b & 0.237 & 0.750 & 0.391 & 0.175 & 6.33 \\
4-c & 0.926 & 0.250 & 0.000 & 0.144 & 5.12 \\
4-d & 0.510 & 0.750 & 0.527 & 0.574 & 5.69 \\
4-e & 0.747 & 0.500 & 0.106 & 0.519 & 5.42 \\
4-f & 0.000 & 1.000 & 0.810 & 0.000 & 6.59 \\
5-a & 1.000 & 0.000 & 1.000 & 0.000 & 5.01 \\
5-b & 0.747 & 0.500 & 0.303 & 0.514 & 5.63 \\
5-c & 0.926 & 0.250 & 0.222 & 0.164 & 5.09 \\
5-d & 0.237 & 0.750 & 0.612 & 0.154 & 6.20 \\
5-e & 0.689 & 0.500 & 0.614 & $\mathbf{0 . 5 8 5}$ & 5.27 \\
5-f & 0.000 & 1.000 & 1.000 & 0.000 & 5.56 \\
5-g & 0.510 & 0.750 & 0.568 & 0.583 & 5.56 \\
5-h & 0.179 & 0.750 & 0.898 & 0.063 & 19 \\
\hline
\end{tabular}

The results of fuzzy analogical gates show that Figure (5-e) is the best one as a weight index $(0.585)$ but not as TAC $(\$ 5.27 \mathrm{M})$ followed by Figure $(5-\mathrm{g})(0.583)$ and TAC $(\$ 5.56 \mathrm{M})$, followed by Figure (4-d) (0.574) and TAC $(\$ 5.69 \mathrm{M})$. A comparison of the results for the overall problem suggests that some degree of interzonal heat transfer will be beneficial. The various possible interzonal transfer scenarios identified below can now be examined. It is best to start with the highest level of complexity Figures 4, 5 (a) and results obtained by the fuzzy gates. Table 17 represents the best arrangement of sequence according to the weight index not to TAC.

Table 17.Comparisons of results

\begin{tabular}{|c|c|c|c|c|}
\hline Figures & $\begin{array}{c}\text { MER } \\
(M W)\end{array}$ & $\begin{array}{c}\text { No. of } \\
\text { interzonal } \\
\text { transfer }\end{array}$ & $\begin{array}{c}\text { Cost } \\
(\mathbf{M} \$ / \mathbf{Y r})\end{array}$ & W.I. \\
\hline 4-a & 30.55 & 5 & 4.97 & 0.00 \\
\hline $5-a$ & 30.55 & 5 & 5.01 & 0.00 \\
\hline $5-e$ & 36.65 & 3 & 5.27 & 0.585 \\
\hline $5-g$ & 40.15 & 2 & 5.56 & 0.583 \\
\hline $4-d$ & 40.15 & 2 & 5.69 & 0.574 \\
\hline 4-e & 35.50 & 3 & 5.42 & 0.519 \\
\hline $5-b$ & 35.50 & 3 & 5.63 & 0.514 \\
\hline $4-b$ & 45.50 & 2 & 6.33 & 0.175 \\
\hline $5-c$ & 32.00 & 4 & 5.09 & 0.164 \\
\hline $5-d$ & 45.50 & 2 & 6.02 & 0.154 \\
\hline 4-c & 32.00 & 4 & 5.12 & 0.144 \\
\hline $5-h$ & 46.65 & 2 & 19.0 & 0.063 \\
\hline
\end{tabular}

Figure (4-a) has a MER of $30.55 \mathrm{MW}$ and $\$ 4.97 \mathrm{M}$, also Figure (5-a) has a MER of 30.55 and $\$ 5.01 \mathrm{M}$., but they posses a zero weight index. As is often found with integration problems there are not large differences in the total annual costs of the solutions. The designs involving just three interzonal transfers have annual costs that are between 7 and $10 \%$ higher than those involving five transfers. Piping and other costs have been ignored. Engineering judgment would probably lead to the adoption of the designs involving just three transfers. The best one from the view point of fuzzy analogical gates is figure 5-e which posses the greatest weight index (0.585) followed by Figure 5-g. the final process flowsheet for three interzonal transfer is shown in Figure 6.

\section{CONCLUSIONS}

The present study explores new technique for synthesis optimum heat integration network between areas, which consist of four sequential steps: deficit cascades and zone problem table to evaluate the minimum number of heat exchanger units, then energy and range targeting are generated for various network structures.

The resulting networks are then subject to normalization of variables parameters followed by two fuzzy analogical gates. The symmetric gate (AND gate) inputs are normalized savings in energy requirement and the number of inter-zonal transfer. The asymmetric gate (Invoke gate) inputs are the output of the AND gate and normalized added area.

It has been found that the results show that the present strategy is excellent in decision making for the optimum area target, number of interzonal transfers and very good indicator to the optimum sequence for alternative distribution cascades compared to total network costs. Simple and can be applied without either the need of cost data or complex mathematical programming such as LP, NLP. Robust, accurate and time saver when there are a large number of alternatives possibilities.

\section{Nomenclature}

$\begin{array}{ll}\text { HE } & \text { Heat Exchangers } \\ \text { HI } & \text { Heat Integration } \\ \text { MER } & \text { Minimum energy requirements } \\ Q_{\text {savings }} & \text { The amount of energy savings in }(\mathrm{MW}) \\ \mathrm{T}_{\mathrm{S}} & \text { Source temperature of stream }\left({ }^{\circ} \mathrm{C}\right) \\ \mathrm{T}_{\mathrm{T}} & \text { Target temperature of stream }\left({ }^{\circ} \mathrm{C}\right) \\ \mathrm{CP} & \text { specific heat }\left(\mathrm{MW} /{ }^{\circ} \mathrm{C}\right) \\ \mathrm{W} . \mathrm{I} & \text { Weight Index } \\ \mu_{1} & \text { First AND gate input } \\ \mu_{2} & \text { Second AND gate input } \\ \mu_{3} & \text { Invoke gate input } \\ \mathrm{LP} & \text { Linear Programming } \\ \mathrm{NLP} & \text { Non Linear Programming }\end{array}$


International Journal of Computer Applications (0975 - 8887)

Volume 96-No.5, June 2014

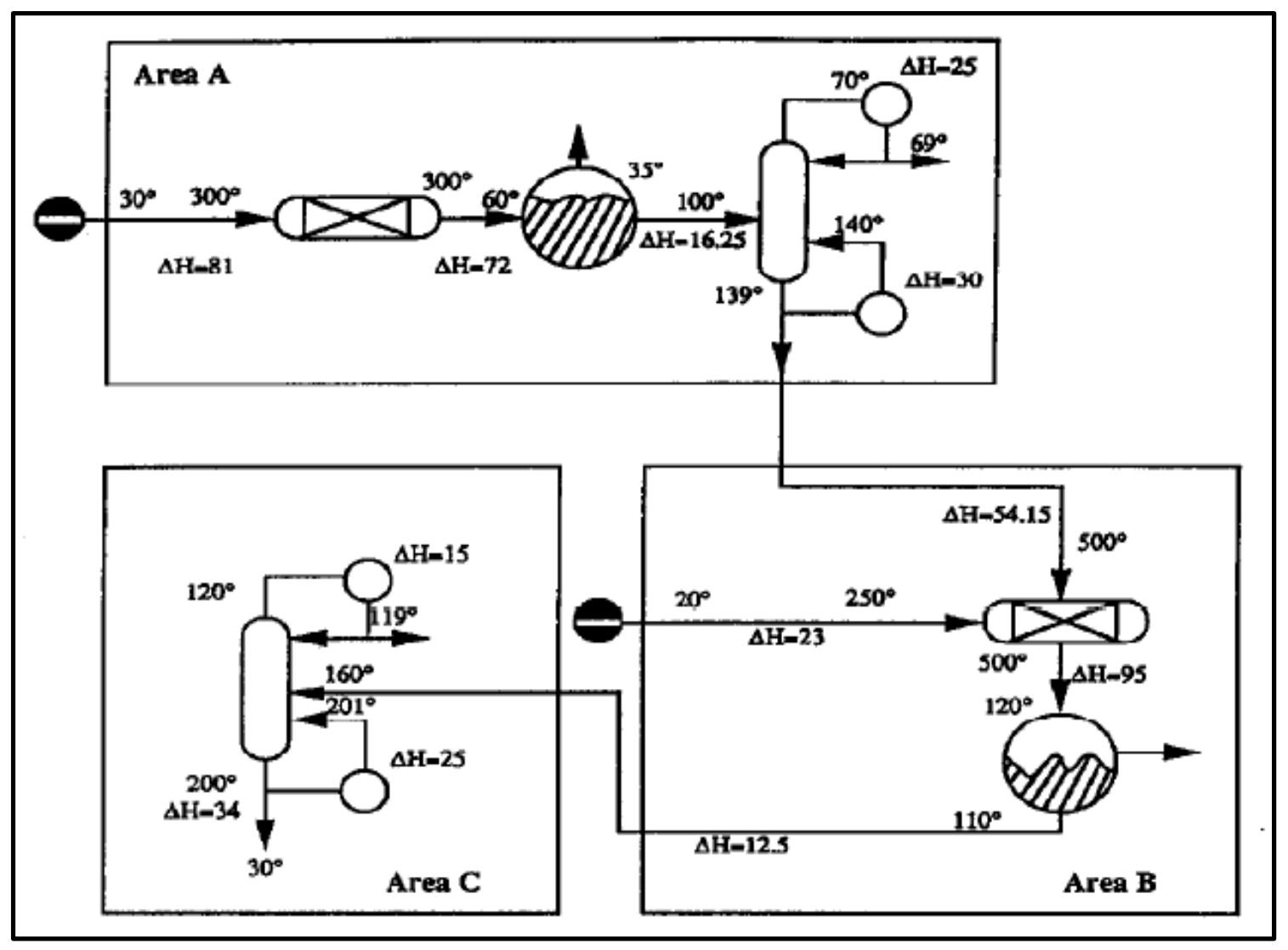

Fig. 3. Process flowsheet for Ahmad and Hui problem.

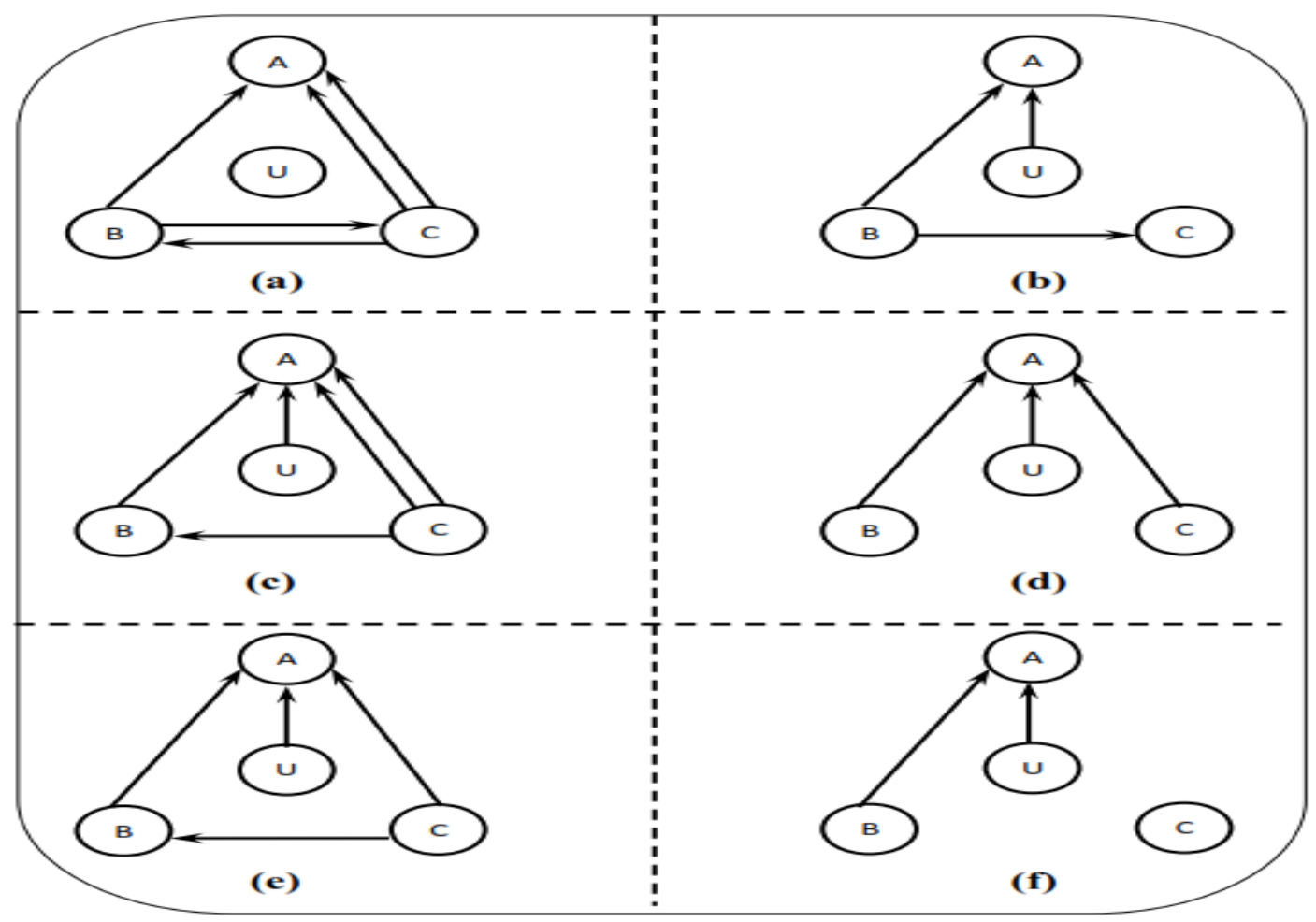

Fig. 4. Alternative Utility Distribution.

21 


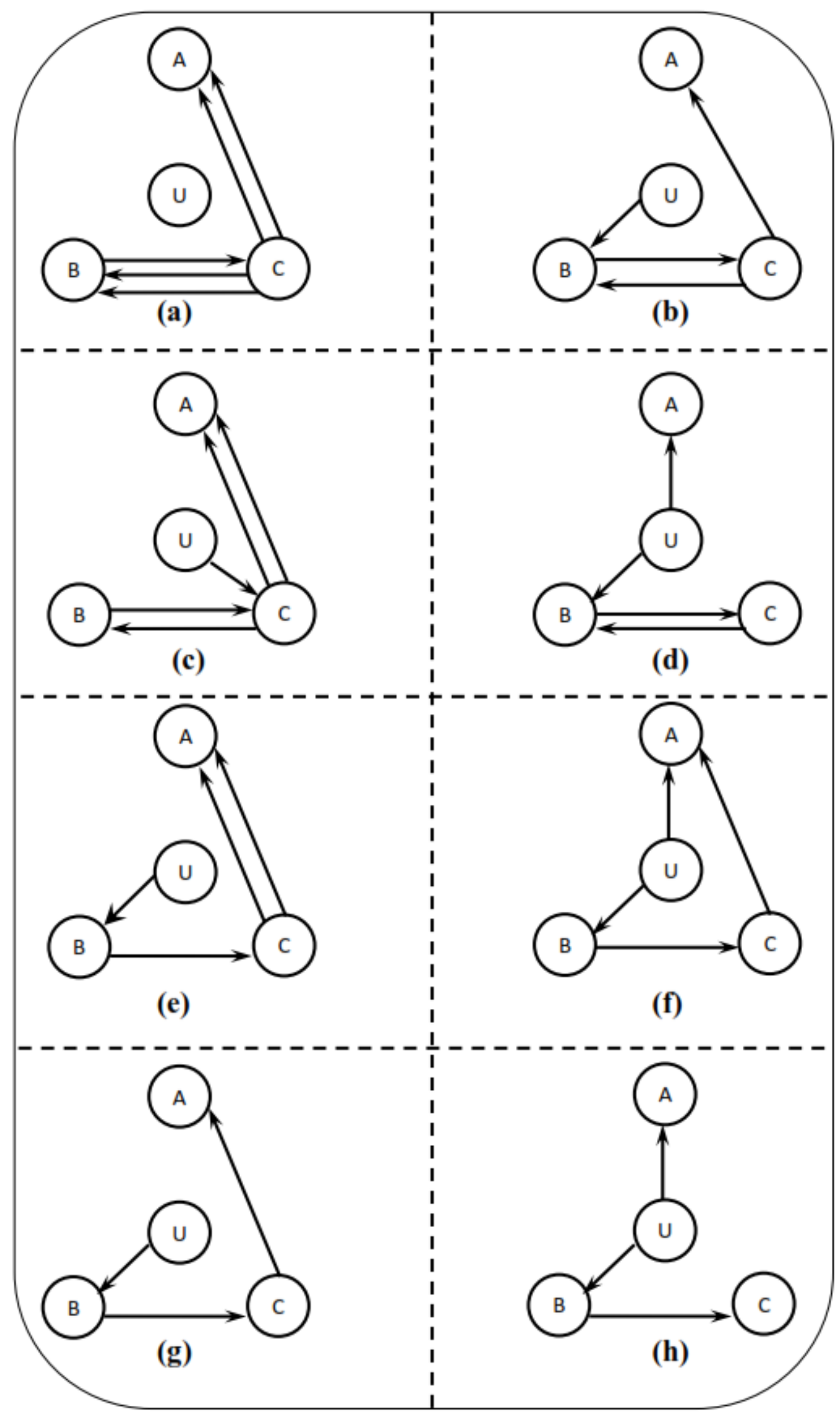

Fig. 5. Alternative Utility Distribution. 


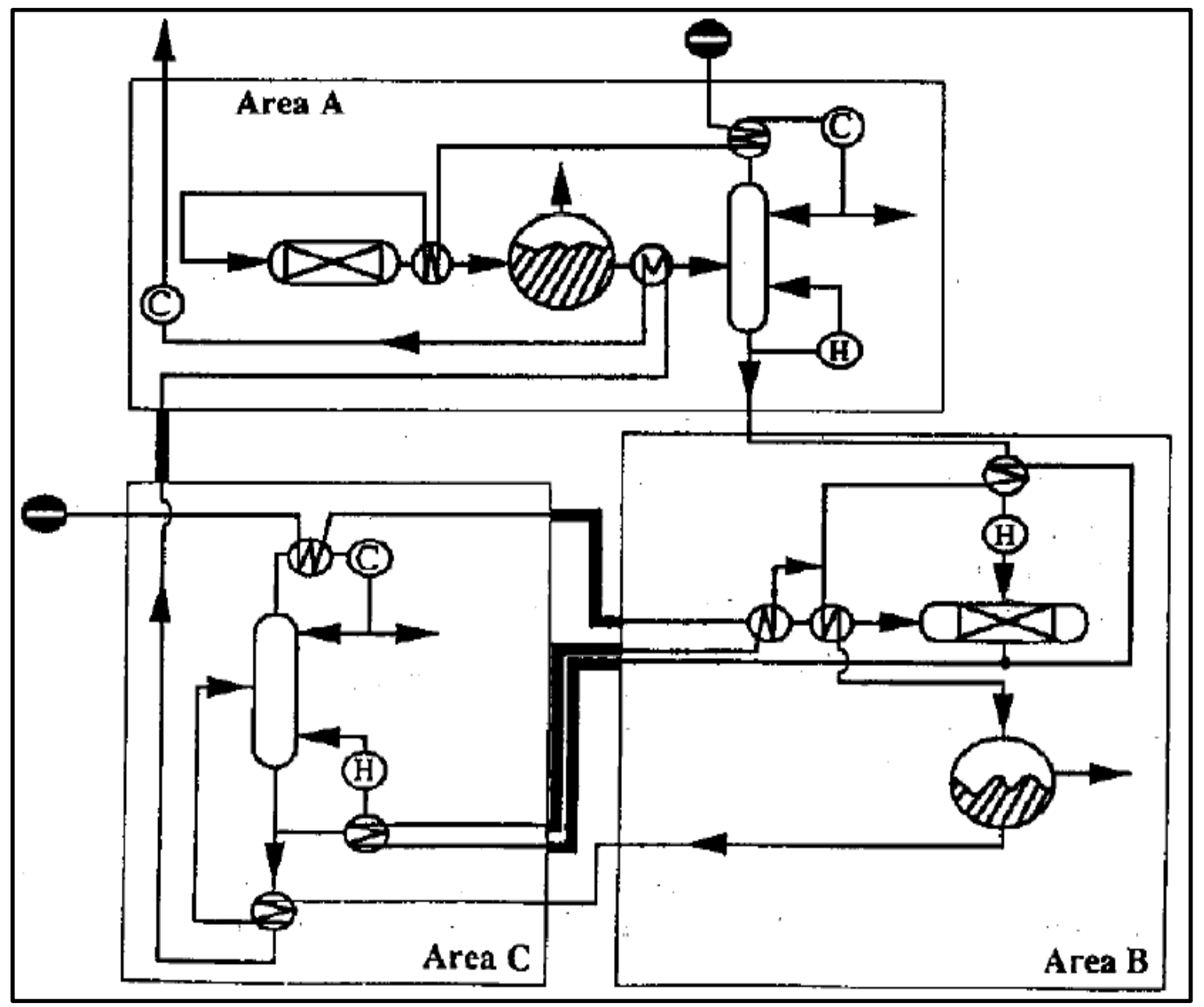

Fig. 6. Final Process flowsheet [14].

\section{REFERENCES}

[1] Chemical Process: Design and Integration by Robin M. Smith et al. Manchester, UK: John Wiley \& Sons Ltd.; 2005. The third key book, an extension and update of book published in 1995 .

[2] Ponton JW, Donaldson RAB: A fast method for the synthesis of optimal heat exchanger networks. Chem Eng Sci 1974, 29:2375-2377.

[3] Gundersen T, Naess L: The synthesis of cost optimal heat exchanger networks: an industrial review of the state of the art. Heat Recovery System CHP (presently Application Thermal Enginering) 1990, 10:301-328. A comprehensive HEN synthesis review for developments up to year 1990 .

[4] Nishida N, Liu YA, Lapidus L: Studies in chemical process design and synthesis: III. A simple and practical approach to the optimal synthesis of heat exchanger networks. AIChE J 1977, 23:77-93. One of the early key contributions to HEN synthesis setting the bases for HI.

[5] Furman KC, Sahinidis NV: A critical review and annotated bibliography for heat exchanger network synthesis in the 20th century. Ind Eng Chem Res 2002,
41:2335-2370.

[6] Linnhoff B, Townsend DW, Boland D, Hewitt GF, Thomas BEA, Guy AR, Marsland RH: A user guide on process integration for the efficient use of energy. Rugby, UK: IChemE; 1982.

[7] Smith R: Chemical Process Design. New York, USA: McGraw-Hill; 1995

[8] Smith R, Klemes J, Tovazhnyansky LL, Kapustenko PA, Uliev LM: Foundations of heat processes integration. Kharkiv, Ukraine: NTU KhPI; 2000, (in Russian).

[9] Linnhoff B, Townsend DW, Boland D, Hewitt GF, Thomas BEA, Guy AR, Marsland RH: A user guide on process integration for the efficient use of energy. Rugby, UK: IChemE; 1994

[10] Kemp IC (authors of the first edition Linnhoff B,Townsend DW, Boland D, Hewitt GF, Thomas BEA, Guy AR, Marsland R): Pinch analysis and process integration. A user guide on process integration for efficient use of energy. Amsterdam, the Netherlands: Elsevier; 2007

[11] Gundersen T: Heat integration-targets and heat 
exchanger network design. In Handbook of Process Integration (PI): $\quad$ (chapter http://www.ivt.ntnu.no/ept/fag/tep4215/innhold/Handboo $\mathrm{k} \% 20$ of\%20PI\%20-\%20Chapter\%202-1.pdf

[12] Klemes. JJ. (Ed): Process integration handbook. Cambridge, UK: Woodhead Publishing/Elsevier; $\begin{array}{llllll}2013978 & 0 & 85709 & 593 & 0 & \text { http:// }\end{array}$ dx.doi.org/10.1533/9780857097255.1.3.

[13] Klemes.JJ and Zdravko Kravanja2, Forty years of Heat Integration: Pinch Analysis (PA)land Mathematical Programming (MP) Elsevier; 2013, 2:461-474. This review comes from a themed issue on Process systems engineering Edited by Ferenc Friedler and Ka Ming Ng Available online 16th November2013 http://dx.doi.org/10.1016/j.coche.2013.10.003

[14] Ahmad S. and Hui D. C. W Heat Recovery Between Areas of Integrity Computers \& Chem. Engng, Vol. 15, No. 12, pp. 809-832, 1991
[15] Flower JR, Linnhoff B: Synthesis of heat exchanger networks - 2. Evolutionary generation of networks with various criteria of optimality. AIChE J 1978, 24:642-654.

[16] Amidpour. M. Polley. G.T., Application of problem decomposition in process integration, Trans IChem E, volume 75 part A, 53-63 January 1997 http://www.researchgate.net/publication/234053642

[17] Kemp, I. C. and Deakin, A. W., 1989, The cascade analysis for energy and process integration of batch processes, Chem Eng Res Des, 67A: 495-525.

[18] Hussein M.H., Moselhy H., Aly S., Awad M. E. 2013.'A New Strategy to Synthesis an Optimum Controllable HEN by using Fuzzy Analogical Gates' International Journal of Computer Applications Volume 83 - No3, December 2013, 41-55 